\title{
Study of product composition of the reaction between \\ 1,1,2,2-tetrabromoethane and imidazole or 1,2,4-triazole in a superbasic medium
}

Maxim Klyuchenko, Pulat Kadirov, Anastasiya Kuznetsova, Andrei Potapov National Research Tomsk Polytechnic University, 30 Lenin Ave., Tomsk, 634050, Russia

E-mail: potapov@tpu.ru

\begin{abstract}
Influence of reagent ratio on the composition of products of the reaction between 1,1,2,2-tetrabromoethane and imidazole or 1,2,4-triazole in a superbasic medium (potassium hydroxide - dimethyl sulfoxide) was investigated using GC/MS technique. It was found that nucleophilic substitution reaction is always accompanied by elimination reactions (dehydrobromination and debromination). In addition to 1,1,2,2-tetra(azol-1-yl)ethane, 1,1,2-tri(azol-1-yl)ethenes and 1,2-di(azol-1$\mathrm{yl})$ ethenes, as well as 1,2-di(azol-1-yl)-1-bromoethenes were detected. Reaction pathway that explains the formation of all major products was proposed.
\end{abstract}

Keywords: imidazole, triazole, terabromoethane, superbasic medium, nucleophilic substitution, elimination 


\section{Introduction}

Compounds bearing several heterocyclic moieties can act as multidentate ligands for the construction of metal-organic frameworks (MOFs) [1-4]. Constant design of new MOFs is stimulated by their high capacity for gas storage [5-7], photophysical properties [8], sensor capabilities [9] and excellent catalytic performance [10].

Tetra(pyrazolyl)derivatives were successfully used for preparation of coordination polymers and molecular complexes [11-15]. In our preceding studies we have developed a synthetic procedure for the simplest bitopic tetra(pyrazolyl)derivative 1,1,2,2-tetra(pyrazol-1-yl)ethane [16] and determined the crystal structure of its copper(II) molecular complex [17]. In this communication we report the study of the reaction between 1,2,4-triazole and imidazole and 1,1,2,2-tetrabromoethane with the aim to prepare new tetra(azolyl) polydentate ligands.

\section{Results and discussion}

The reactions between 1,2,4-triazole (or imidazole) and 1,1,2,2-tetrabromoethane (TNE) were carried out in a superbasic medium potassium hydroxide - dimethyl sulfoxide (scheme 1). Molar ratio of reagents (TBE to azole) was varied from 1:1 to $1: 4$, while other parameters (temperature, concentration of the base) were held constant (table 1).

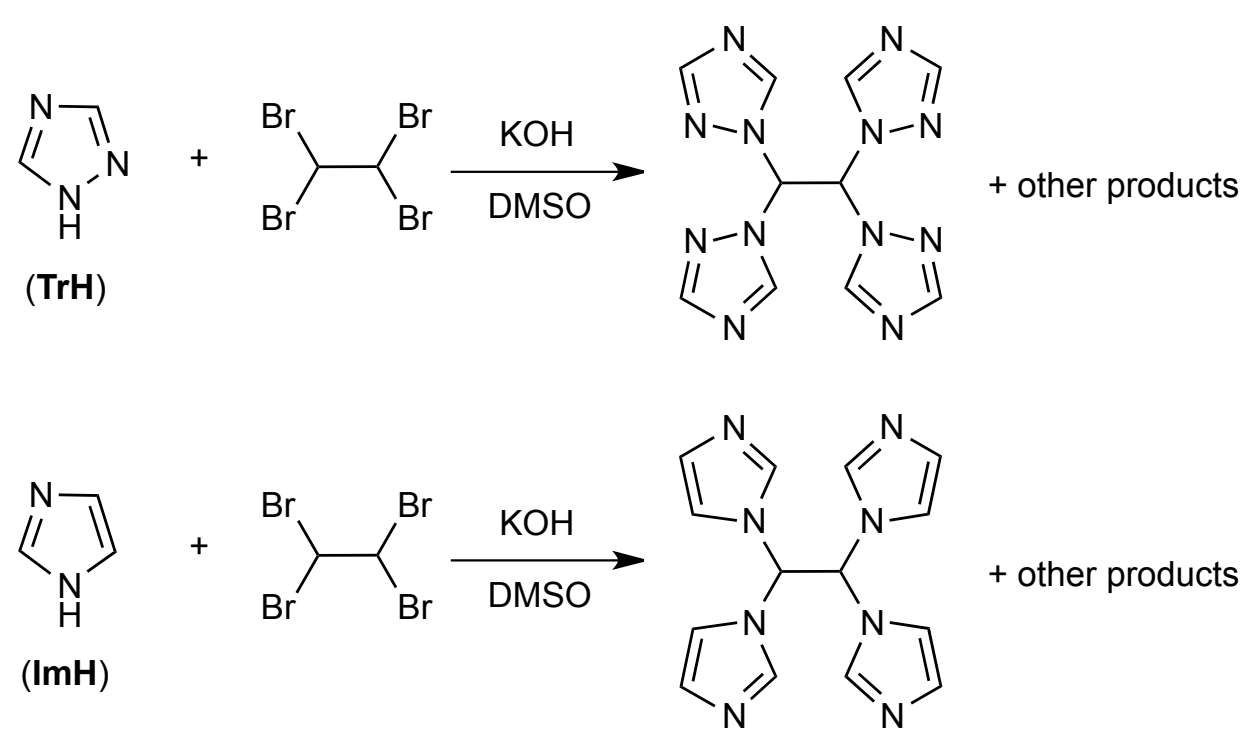

Scheme 1 
Table 1 - Screening of reaction conditions between azoles and TBE

\begin{tabular}{|l|l|l|l|l|l|}
\hline Run & AzH $(\mathrm{mmol})$ & TBE $(\mathrm{mmol})$ & $\mathrm{KOH}(\mathrm{mmol})$ & $\mathrm{DMSO}(\mathrm{ml})$ & $\mathrm{t}\left({ }^{\circ} \mathrm{C}\right)$ \\
\hline A & 1.0 & 1.0 & 2 & 1 & 80 \\
\hline B & 1.0 & 0.5 & 2 & 1 & 80 \\
\hline C & 1.0 & 0.25 & 2 & 1 & 80 \\
\hline
\end{tabular}

As it is well known, under basic conditions nucleophilic substitution reactions are accompanied by elimination reactions [18]. In accordance with this, products of both of these processes were detected in the reaction mixtures (table 2 , scheme 2).

Table 2 - Composition of product mixtures of the reaction between $\mathrm{TrH}$ and TBE

\begin{tabular}{|c|c|c|c|c|c|c|c|c|}
\hline \multirow[t]{2}{*}{ Run } & \multicolumn{8}{|c|}{ Molar \% (GC/MS) } \\
\hline & $\mathrm{Tr}_{4}$ & $\mathrm{Tr}_{3}$ & $\mathrm{Tr}_{2}$ & $\begin{array}{l}\mathrm{Tr}_{2} \mathrm{Br} \\
(\mathrm{E} \& \mathrm{Z})\end{array}$ & $\begin{array}{l}\mathrm{TrBr}_{2} \\
(\mathrm{E} \& \mathrm{Z})\end{array}$ & $\begin{array}{l}\text { gem- } \\
\mathrm{TrBr}_{2}\end{array}$ & $\mathrm{Tr}_{2} \mathrm{CH}_{2}$ & $\left(\mathrm{Tr}_{2} \mathrm{C}\right)_{2}$ \\
\hline $\begin{array}{l}\text { R.T. } \\
(\min )\end{array}$ & 19.5 & 16.7 & 12.4 & $\begin{array}{c}15.1 \\
15.4\end{array}$ & 14.6 & 11.3 & 10.4 & 21.5 \\
\hline $\begin{array}{l}M \\
(\mathrm{~g} / \mathrm{mol})\end{array}$ & 298 & 229 & 162 & 241 & 252 & 253 & 150 & 296 \\
\hline$A$ & $\bar{L}$ & $92.0 \%$ & 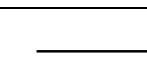 & $30.0 \%$ & $56.0 \%$ & 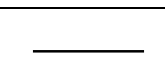 & - & $4.9 \%$ \\
\hline$B$ & $7.0 \%$ & $19.7 \%$ & 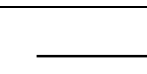 & $19.5 \%$ & $49.0 \%$ & $14.8 \%$ & & $3.7 \%$ \\
\hline $\mathrm{C}$ & $17.6 \%$ & $33.1 \%$ & $8.3 \%$ & & 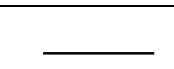 & 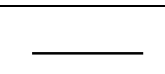 & $39.5 \%$ & - \\
\hline
\end{tabular}

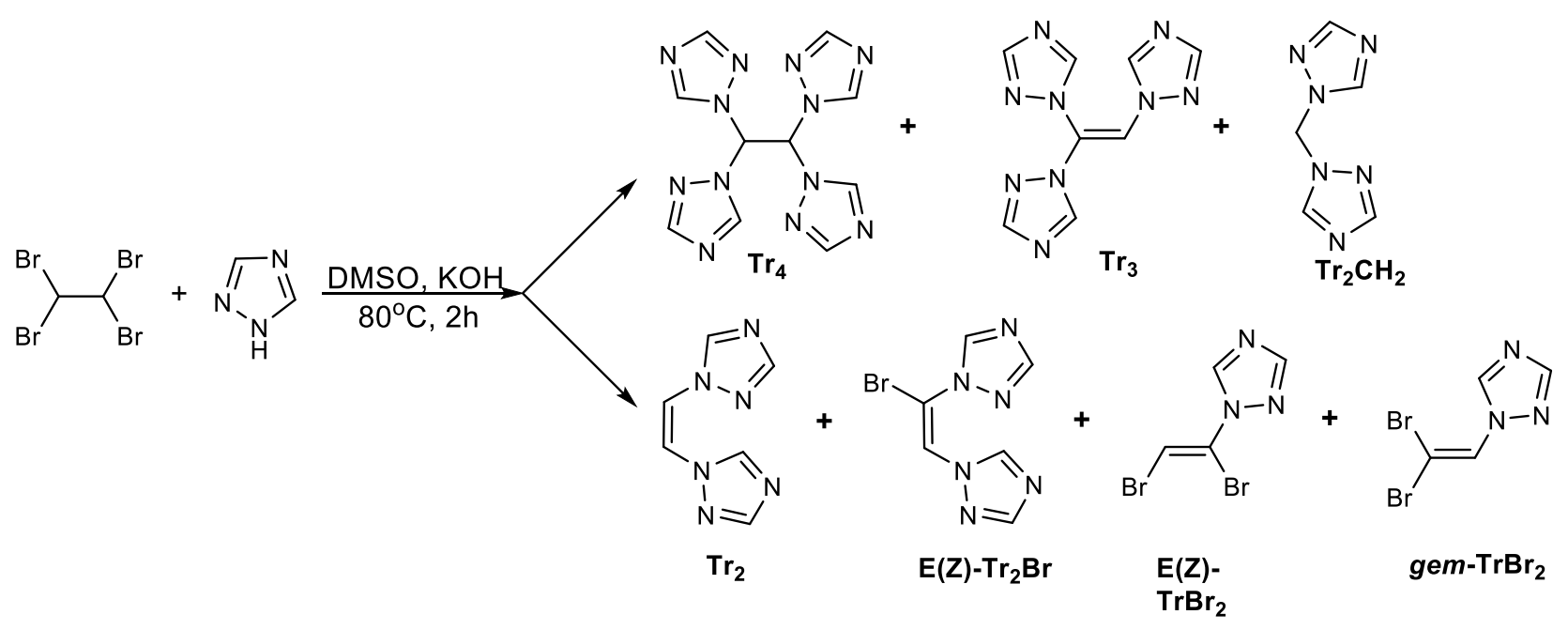

Scheme 2 
Reaction with imidazole gave similar results and is not discussed in detail in this communication.

\section{Experimental}

A suspension of $1 \mathrm{mmol}$ of 1,2,4-triazole (or imidazole), $2 \mathrm{mmol}$ of $\mathrm{KOH}, 0.25$ $1 \mathrm{mmol}$ of TBE in $1 \mathrm{ml}$ of DMSO were incubated at $80^{\circ} \mathrm{C}$. The reaction progress was monitored by TLC. After two hours, full conversion of the starting azole was achieved. The reaction mixtures were diluted with water $(5 \mathrm{ml})$, DMSO-water mixture was removed on a rotary evaporator, the residue was treated by methylene chloride to extract the organic products, which were then analyzed by GC/MS method.

Gas chromatography-mass spectrometry analysis was performed using Agilent 7890A gas chromatograph equipped with Agilent MSD 5975C mass-selective detector. The relative quantities of the products were determined from peak areas without correction coefficients.

\section{Summary}

In all the cases, the reactions yielded complex product mixtures, in which triazolyland bromo-substituted ethenes were the dominating components.

When triazole reacted with TBE in 1:1 ratio, bromoethenes containing one or two triazole rings were the major products.

For 2:1 TrH-TBE reaction, 1,1,2-tris(triazol-1-yl)ethane $\operatorname{Tr}_{3}$ was detected as a second to the dominating product.

In case of 4:1 $\mathrm{TrH}$-TBE ratio, $\mathrm{Tr}_{3}$ was obtained as a major product, while only little amount of $\mathrm{Tr}_{4}$ was formed and no $\mathrm{TrBr}_{2}$ was detected at all.

\section{Acknowledgements}

The reported study was supported by the Russian Scientific Fund, grant No. 1513-10023.

\section{References}

[1] G.A. Senchyk, A.B. Lysenko, H. Krautscheid, E.B. Rusanov, A.N. Chernega, K.W. Krämer, et al., Functionalized adamantane tectons used in the design of mixed-ligand copper(II) 1,2,4-triazolyl/carboxylate metal-organic 
frameworks, Inorg. Chem. 52 (2013) 863-872. doi:10.1021/ic3020157.

[2] D.L. Reger, E.A. Foley, M.D. Smith, Structural impact of multitopic thirdgeneration bis(1-pyrazolyl)methane ligands: double, mononuclear metallacyclic silver(I) complexes, Inorg. Chem. 49 (2010) 234-242. doi:10.1021/ic901899r.

[3] K.T. Prasad, B. Therrein, K.M. Rao, Syntheses and characterization of mono and dinuclear complexes of platinum group metals bearing benzene-linked bis(pyrazolyl)methane ligands, J. Organomet. Chem. 695 (2010) 1375-1382.

[4] S. Bieller, F. Zhang, M. Bolte, J.W. Bats, H.-W. Lerner, M. Wagner, Bitopic Bis- and Tris(1-pyrazolyl)borate Ligands: Syntheses and Structural Characterization, Organometallics. 23 (2004) 2107-2113. doi:10.1021/om049954e.

[5] M. Eddaoudi, J. Kim, N. Rosi, D. Vodak, J. Wachter, M. O'Keeffe, et al., Systematic design of pore size and functionality in isoreticular MOFs and their application in methane storage., Science. 295 (2002) 469-72. doi:10.1126/science.1067208.

[6] J.-R. Li, R.J. Kuppler, H.-C. Zhou, Selective gas adsorption and separation in metal-organic frameworks., Chem. Soc. Rev. 38 (2009) 1477-504. doi:10.1039/b802426j.

[7] K. Sumida, D.L. Rogow, J.A. Mason, T.M. McDonald, E.D. Bloch, Z.R. Herm, et al., Carbon dioxide capture in metal-organic frameworks., Chem. Rev. 112 (2012) 724-81. doi:10.1021/cr2003272.

[8] Y. Cui, Y. Yue, G. Qian, B. Chen, Luminescent functional metal-organic frameworks., Chem. Rev. 112 (2012) 1126-62. doi:10.1021/cr200101d.

[9] L.E. Kreno, K. Leong, O.K. Farha, M. Allendorf, R.P. Van Duyne, J.T. Hupp, Metal-organic framework materials as chemical sensors., Chem. Rev. 112 (2012) 1105-25. doi:10.1021/cr200324t.

[10] A.H. Chughtai, N. Ahmad, H.A. Younus, A. Laypkov, F. Verpoort, Metalorganic frameworks: versatile heterogeneous catalysts for efficient catalytic organic transformations., Chem. Soc. Rev. 44 (2015) 6804-49. doi:10.1039/c4cs00395k. 
[11] D.L. Reger, J.R. Gardinier, T.C. Grattan, M.R. Smith, M.D. Smith, Synthesis of the silver(I) complex of $\mathrm{CH} 2[\mathrm{CH}(\mathrm{pz} 4 \mathrm{Et}) 2] 2$ containing the unprecedented [Ag(NO3)4]3- anion: A general method for the preparation of 4(alkyl)pyrazoles, New J. Chem. 27 (2003) 1670-1677.

[12] D.L. Reger, R.P. Watson, M.D. Smith, P.J. Pellechia, Controlling the addition of metal centers to a bis(pyrazolyl)methane starburst ligand: Direct routes to mono-, bi-, and trimetallic rhenium(I) complexes, Organometallics. 25 (2006) 743-755.

[13] D.L. Reger, J.R. Gardinier, R.F. Semeniuc, M.D. Smith, Silver complexes of 1,1,3,3-tetrakis(pyrazol-I-yl)propane: The "quadruple pyrazolyl embrace" as a supramolecular synthon, Dalt. Trans. (2003) 1712-1718.

[14] D.L. Reger, R.P. Watson, J.R. Gardinier, M.D. Smith, Impact of variations in design of flexible bitopic bis(pyrazolyl)methane ligands and counterions on the structures of silver(I) complexes: Dominance of cyclic dimeric architecture, Inorg. Chem. 43 (2004) 6609-6619.

[15] N. Dehury, S.K. Tripathy, A. Sahoo, N. Maity, S. Patra, Facile tandem Suzuki coupling/transfer hydrogenation reaction with a bis-heteroscorpionate $\mathrm{Pd}-\mathrm{Ru}$ complex, Dalt. Trans. 43 (2014) 16597-16600. doi:10.1039/C4DT02465F.

[16] A.S. Potapov, E.A. Nudnova, A.I. Khlebnikov, V.D. Ogorodnikov, T. V Petrenko, Synthesis of new polydentate pyrazolyl-ethene ligands by interaction of $1 \mathrm{H}$-pyrazole and 1,1,2,2-tetrabromoethane in a superbasic medium, J. Heterocycl. Chem. 48 (2011) 645-651. doi:10.1002/jhet.566.

[17] A.S. Potapov, E.A. Nudnova, A.I. Khlebnikov, V.D. Ogorodnikov, T. V Petrenko, Synthesis, crystal structure and electrocatalytic activity of discrete and polymeric copper(II) complexes with bitopic bis(pyrazol-1-yl) methane ligands, Inorg. Chem. Commun. 53 (2015) 72-75.

[18] V.J. Shiner, Substitution and Elimination Rate Studies on Some Deuteroisopropyl Bromides, J. Am. Chem. Soc. 74 (1952) 5285-5288. doi:10.1021/ja01141a014. 